\title{
ORIGINAL
}

\section{Association of IRS-1 and IRS-2 genes polymorphisms with polycystic ovary syndrome: a meta-analysis}

\author{
Yuan Ruan, Jianhua Ma and Xiaojing Xie \\ Department of Endocrinology, Nanjing First Hospital, Nanjing Medical University, Nanjing 210006, China
}

\begin{abstract}
Insulin resistance (IR) plays an important role in the pathogenesis of polycystic ovary syndrome (PCOS) which is a common disorder in premenopausal women. The association between the single nucleotide polymorphisms (SNPs) of insulin receptor substrate (IRS) gene and PCOS in several populations has been studied, but the results are conflicting. The aim of this study was undertaken to investigate association of IRS-1 and IRS-2 genes polymorphisms with PCOS by conducting a meta-analysis. Literature search was conducted through PubMed and EMBASE databases (up to July 31, 2011). Fifteen articles with 1,358 cases and 1,561 controls were enrolled in the meta-analysis of the association between Gly972Arg variant and PCOS, and five articles with 519 cases and 883 controls were enrolled in the meta-analysis of Gly1057Asp variant. Summary odds ratios (ORs) and 95\% confidence intervals (CIs) were estimated using fixed and random-effects models. The Q-statistic test was used to assess heterogeneity, and Begg's test and Egger's test were used to evaluate publication bias. Sensitivity analysis was also performed. Our results indicated that A allele of Gly972Arg conferred a significantly increased risk of PCOS compared with G allele (OR $=1.91,95 \%$ CI: 1.36-2.68). However, in Gly1057Asp polymorphism the OR of allele A vs. G is 0.92 (95\% CI: 0.72, 1.18). Our meta-analysis suggested that IRS-1 Gly972Arg polymorphism might be considered a significant risk for PCOS. Otherwise, no significant associations were observed in IRS-2 Gly1057Asp polymorphism which needs to be further confirmed by further studies.
\end{abstract}

Key words: Insulin receptor substrate, Polymorphisms, Polycystic ovary syndrome, Meta-analysis

POLYCYSTIC OVARY SYNDROME (PCOS) is one of the most common heterogeneous endocrine disorders, which affect $5 \%-10 \%$ of women in reproductive age and is a leading causes of female infertility [1]. It is characterized by menstrual irregularity, hyperandrogenism, insulin resistance, and increased risk of type 2 diabetes mellitus (T2DM) and cardiovascular disease (CVD) [2, 3]. Candidate genes for etiology of PCOS involve in ovarian and adrenal steroidogenesis, steroid hormone actions, gonadotropin action and regulation, insulin action and secretion, energy homeostasis, chronic inflammation and others [4]. Yet the "PCOS genes" remain elusive. Insulin resistance is a key component in the pathogenesis of PCOS and the predisposition to type 2 diabetes $[5,6]$, however, the mechanisms for defects in insulin signaling in the disorder are com-

Submitted Dec. 16, 2011; Accepted Apr. 3, 2012 as EJ11-0387 Released online in J-STAGE as advance publication Apr. 21, 2012

Correspondence to: Jianhua Ma, Department of Endocrinology, Nanjing First Hospital, Nanjing Medical University, Nanjing 210006,China. E-mail:majianhua@china.com plex and have not been fully elucidated $[7,8]$.

Insulin receptor substrates proteins (IRS) are critical for insulin mediated signal transduction in insulin target tissues. Several studies have shown that two common polymorphisms in IRS particularly Gly972Arg (rs1801278) in IRS-1 and Gly1057Asp (rs1805097) in IRS-2 have been shown to influence the susceptibility to T2DM and are associated with phenotypic features of PCOS [9-15]. A recent meta-analysis of eleven studies (889 cases, 1303controls) yielded a significant association for IRS-1 Gly972Arg polymorphism concerning the Gly/Arg vs. Gly/Gly genotype with the risk of developing PCOS [16]. However, some new articles reported associations of Gly972Arg and Gly1057Asp polymorphisms with PCOS, but the results of these studies were conflicting. In this study, we try to perform a robust meta-analysis on recently literatures for a better understanding of the susceptibility of the IRS-1 and IRS-2 gene variants in the development of PCOS. 


\section{Material and Methods}

\section{Search strategy and inclusion criteria}

All studies published before July 2011 were identified by extended computer-based searches of the PubMed and EMBASE databases. The following key words or combination of term were used: 'insulin receptor substrate-1,' 'IRS-1,' 'Gly972Arg,' 'G972R,' 'rs1801278,' 'insulin receptor substrate-2,' 'IRS-2,' 'Gly1057Asp,' 'G1057D,' 'rs1805097,' 'variant,' 'polymorphism' and 'genotype' coupled with the term 'Polycystic ovary syndrome,' 'Polycystic ovaries.' References of retrieved articles were also screened. Case reports, editorials, review articles and studies based on pedigree data were excluded. The search was restricted to articles in English. Studies included in the meta-analysis had to meet all the following criteria: (a) unrelated case-control design; (b) available genotype or allele frequency; (c) cases were patients with PCOS, and healthy unrelated controls.

\section{Data extraction and quality evaluation}

The extracted data included information about first author, year of publication, country of origin, ethnicity of study population, clinical characteristics, number of cases and controls, distribution of genotypes and allele frequencies for both cases and controls. The two polymorphisms for cases and controls were calculated. The data extraction and quality evaluation are carried out by two reviewers independently. The third reviewer would participate the debating if the two reviewers have any disagreements on the data, and the final decision will be adjusted according to the opinions of all three reviewers.

\section{Statistical analysis}

Hardy-Weinberg Equilibrium (HWE) was tested by a goodness-of-fit to compare the observed genotype frequencies to the expected ones among the control subjects. Software Review Manager 5.0 (provided by The Cochrane Collaboration) was used for meta-analysis. Odds ratios (OR) with the corresponding 95\% confidence interval (CI) was applied in all contrasts to detect the association of Gly972Arg polymorphism of the IRS-1 and Gly1057Asp polymorphism of the IRS-2 with the risk of PCOS. Heterogeneity between studies was quantified using the Q-statistic; if $P$ value $<0.10$ [17], the heterogeneity was considered statistically significant. Therefore, if $P$ value $<0.10$, random effects (RE) models were used for the meta-analysis [18]. The inconsistency index $\left(\mathrm{I}^{2}\right)$ was also used to test the heterogeneity. This index is independent of the number of studies included in the meta-analysis. If $\mathrm{I}^{2}<25 \%$, it was considered as absent of heterogeneity; if $\mathrm{I}^{2}=25-50 \%$, as moderate heterogeneity and if $\mathrm{I}^{2}$ $>50 \%$, as large heterogeneity. To assess the publication bias and small-study bias, funnel plot of the data was applied. In addition, Begg's test and Egger's test was also used with software STATA package version 10.0 (Stata Corporation, College Station, Texas). To detect publication bias, sensitivity analysis was undertaken by removing the unreliable study deviated from Hardy-Weinberg equilibrium in the control group then performing meta-analysis again.

\section{Result}

\section{Eligibility of studies}

The literature review identified 21 titles in PubMed and 26 titles in EMBASE that met the search criterion. After review, a total of 16 published articles reported on the relationship between these two IRS gene polymorphisms and PCOS met the inclusion criteria [12-15, 19-29], 15/16 were about the Gly972Arg polymorphism, 5/16 were about the Gly1057Asp polymorphism. These articles were published between 2001 and 2011. In the eligible studies, there were 13 studies of Caucasian and 3 studies of Asian. All studies were cross-sectional case-control studies with sufficient data to calculate the possible relationship between the two polymorphisms and PCOS. All used studies were published in English. The genotypes Gly972Arg included in the first meta-analysis were summarized in (Table 1), the genotypes Gly1057Asp included in the second meta-analysis were summarized in (Table 2). The distribution of genotypes in the controls of all studies is consistent with Hardy-Weinberg equilibrium except for four studies [12, 15, 18, 19], which were tested in the sensitivity analyses.

\section{Gly972Arg polymorphism}

In the fifteen eligible studies, significant associations between the risk of PCOS and the variant genotypes of Gly972Arg polymorphism of the IRS-1 were found in all genetic models except AA vs. GG shown in (Table 3, Fig. 1), dominant model comparison $\mathrm{AA}+\mathrm{AG}$ vs. GG $(P<0.0001, \mathrm{RE} \mathrm{OR}=2.17,95 \%$ $\left.\mathrm{CI}=1.47-3.19, \mathrm{P}_{\text {heterogeneity }}=0.02\right)$, heterozygote com- 
Table 1 Distribution of the IRS-1 Gly972Arg genotype for cases and controls and the allele frequencies.

\begin{tabular}{|c|c|c|c|c|c|c|c|c|c|}
\hline \multirow[b]{2}{*}{ First author, year } & \multirow{2}{*}{$\begin{array}{c}\text { Country } \\
\text { of } \\
\text { women }\end{array}$} & \multirow[b]{2}{*}{ Ethnicity } & \multicolumn{3}{|c|}{ Case } & \multicolumn{3}{|c|}{ Control } & \multirow{2}{*}{$\begin{array}{l}P \text {-value } \\
\text { HWE }\end{array}$} \\
\hline & & & $(n)^{b}$ & $\begin{array}{c}\text { Genotypes } \\
\text { GG/GA/AA }\end{array}$ & $\begin{array}{l}\text { Alleles } \\
\text { G/A(\%) }\end{array}$ & $(n)^{b}$ & $\begin{array}{c}\text { Genotypes } \\
\text { GG/GA/AA }\end{array}$ & $\begin{array}{l}\text { Alleles } \\
\text { G/A(\%) }\end{array}$ & \\
\hline El Mkadem, 2001 [12] & France & Caucasian & 53 & $41 / 12 / 0$ & 88.7/11.3 & 102 & $85 / 17 / 0$ & $91.7 / 8.3$ & 0.359 \\
\hline Sir-Petermann, 2001 [29] & Chile & Caucasian & 82 & $72 / 10 / 0$ & 93.9/6.1 & 70 & $66 / 4 / 0$ & $97.1 / 2.9$ & 0.806 \\
\hline Witchel, 2001 [28] & USA & Caucasian & 69 & $53 / 16 / 0$ & $88.4 / 11.6$ & 15 & $14 / 1 / 0$ & $96.7 / 3.3$ & 0.894 \\
\hline Sir-Petermann, 2004 [27] & Chile & Caucasian & 143 & $129 / 14 / 0$ & $95.1 / 4.9$ & 97 & $93 / 4 / 0$ & $97.9 / 2.1$ & 0.084 \\
\hline Witchel, 2005 [26] & USA & Caucasian & 109 & $94 / 15 / 0$ & 93.1/6.88 & 95 & $89 / 6 / 0$ & $96.8 / 3.2$ & 0.751 \\
\hline Dilek, 2005 [14] & Turkey & Caucasian & 60 & $46 / 14 / 0$ & 88.3/11.7 & 60 & $55 / 5 / 0$ & $95.8 / 4.2$ & 0.736 \\
\hline Villuendas, 2005 [13] & Spain & Caucasian & 103 & $90 / 13 / 0$ & 93.7/6.31 & 48 & $41 / 7 / 0$ & $92.7 / 7.3$ & 0.586 \\
\hline Haap, 2005 [23] & Germany & Caucasian & 56 & $50 / 6 / 0$ & $94.6 / 5.36$ & 316 & $272 / 44 / 0$ & $93.0 / 7.0$ & 0.183 \\
\hline Lin TC, 2006 [15] & Taiwan & Asian & 47 & $47 / 0 / 0$ & $100 / 0$ & 45 & $45 / 0 / 0$ & $100 / 0$ & $\mathrm{NA}^{\mathrm{a}}$ \\
\hline Baba, 2007 [25] & Japan & Asian & 123 & $110 / 12 / 1$ & $94.3 / 5.69$ & 380 & $362 / 17 / 1$ & $97.5 / 2.5$ & 0.109 \\
\hline Valdés, 2008 [24] & Chile & Caucasian & 50 & $42 / 8 / 0$ & $92.0 / 8.0$ & 75 & 70/5/0 & $96.7 / 3.3$ & 0.765 \\
\hline Marioli, 2010 [22] & Greece & Caucasian & 162 & $148 / 12 / 2$ & $95.1 / 4.94$ & 122 & $112 / 9 / 1$ & $95.5 / 4.5$ & 0.114 \\
\hline Dravecka, 2010 [21] & Slovak & Caucasian & 53 & $41 / 12 / 0$ & 88.7/11.3 & 21 & $19 / 2 / 0$ & $95.2 / 4.8$ & 0.819 \\
\hline Christopoulos, 2010 [19] & Greece & Caucasian & 183 & $127 / 47 / 9$ & $82.2 / 17.8$ & 88 & $76 / 10 / 2$ & $92.0 / 8.0$ & 0.036 \\
\hline Pappalardo, 2010 [20] & Italy & Caucasian & 65 & $14 / 50 / 1$ & $60 / 40$ & 27 & $22 / 5 / 0$ & $90.7 / 9.3$ & 0.596 \\
\hline
\end{tabular}

${ }^{\mathrm{a}}$ Not available. ${ }^{\mathrm{b}}(\mathrm{n})$ means the numbers of included cases or controls. HWE: Hardy-Weinberg Equilibrium

Table 2 Distribution of the IRS-2 Gly1057Asp genotype for cases and controls and the allele frequencies.

\begin{tabular}{|c|c|c|c|c|c|c|c|c|c|}
\hline \multirow[b]{2}{*}{ First author, year } & \multirow{2}{*}{$\begin{array}{c}\text { Country } \\
\text { of } \\
\text { women }\end{array}$} & \multirow[b]{2}{*}{ Ethnicity } & \multicolumn{3}{|c|}{ Case } & \multicolumn{3}{|c|}{ Control } & \multirow{2}{*}{$\begin{array}{l}P \text {-value } \\
\text { HWE }\end{array}$} \\
\hline & & & $(\mathrm{n})^{\mathrm{a}}$ & $\begin{array}{c}\text { Genotypes } \\
\text { GG/GA/AA }\end{array}$ & $\begin{array}{c}\text { Alleles } \\
\text { G/A(\%) }\end{array}$ & $(\mathrm{n})^{\mathrm{a}}$ & $\begin{array}{c}\text { Genotypes } \\
\text { GG/GA/AA }\end{array}$ & $\begin{array}{l}\text { Alleles } \\
\text { G/A(\%) }\end{array}$ & \\
\hline El Mkadem, 2001 [12] & France & Caucasian & 53 & $19 / 30 / 4$ & $64.2 / 35.8$ & 102 & $46 / 53 / 3$ & $71.1 / 28.9$ & 0.008 \\
\hline Haаp, 2005 [23] & Germany & Caucasian & 51 & $21 / 21 / 9$ & $61.8 / 38.2$ & 536 & $226 / 241 / 69$ & $64.6 / 35.4$ & 0.705 \\
\hline Villuendas, 2005 [13] & Spain & Caucasian & 103 & $55 / 33 / 15$ & $69.4 / 30.6$ & 48 & $20 / 23 / 5$ & $65.6 / 34.4$ & 0.667 \\
\hline Christopoulos, 2010 [19] & Greece & Caucasian & 183 & $97 / 68 / 18$ & $71.6 / 28.4$ & 88 & $38 / 42 / 8$ & $67.0 / 33.0$ & 0.453 \\
\hline Lin YS, 2011 [18] & Taiwan & Asian & 129 & $19 / 25 / 85$ & $24.4 / 75.6$ & 109 & 33/23/53 & $40.8 / 59.2$ & 0.000 \\
\hline
\end{tabular}

a(n) means the numbers of included cases or controls. HWE: Hardy-Weinberg Equilibrium

parison AG vs. GG $(P=0.0001, \mathrm{RE} \mathrm{OR}=2.16,95 \%$ $\left.\mathrm{CI}=1.46-3.19, \mathrm{P}_{\text {heterogeneity }}=0.02\right)$, homozygote comparison AA vs. GG $(P=0.09$, $\mathrm{RE}$ OR $=2.62,95 \% \mathrm{CI}=0.86$ 7.98, $\mathrm{P}_{\text {heterogeneity }}=0.95$ ), allele contrast (A allele vs. $\mathrm{G}$ allele) $(P<0.0001$, RE OR $=1.97,95 \% \mathrm{CI}=1.45$ 2.67, $\left.\mathrm{P}_{\text {heterogeneity }}=0.14\right)$. The results from the sensitivity analyses (exclusion of studies with the controls not in HWE) also suggested the significant association between the Gly972Arg polymorphism and PCOS except AA vs. GG genetic model (Table 3).

\section{Gly1057Asp polymorphism}

Five studies were included for investigating the association between the Gly1057Asp polymorphism and PCOS. As shown in Table 3, no significant associations were observed under dominant model, A vs.
G , and heterozygote comparison AG vs. GG genetic models: $\left(\mathrm{OR}_{\text {dominant }}=1.09,95 \% \mathrm{CI}_{\text {dominant }}=0.66-1.80\right.$, $\mathrm{P}_{\text {heterogeneity }}=0.01 ; \quad \mathrm{OR}_{\mathrm{AvsG}}=1.18,95 \% \mathrm{CI}_{\mathrm{AvsG}}=0.82$ 1.72, $P_{\text {heterogeneity }}=0.006 ; \quad \mathrm{OR}_{\mathrm{AGvGGG}}=0.93, \quad 95 \%$ $\mathrm{CI}_{\mathrm{AGvSGG}}=0.60-1.43, \mathrm{P}_{\text {heterogeneity }}=0.08$, respectively). The results from the sensitivity analyses in dominant model for allele A, the whole comparison of allele A vs. $\mathrm{G}$ and recessive model also suggested no significant associations between Gly1057Asp polymorphism and PCOS. Significant association was detected under additive model (AA vs. GG): $\mathrm{OR}=1.6395 \% \mathrm{CI}=1.00$ 2.68, $P=0.05$, $\mathrm{P}_{\text {heterogenity }}=0.24$, and recessive model (AA vs. $\quad \mathrm{AG}+\mathrm{GG}$ ): $\mathrm{OR}=1.68, \quad 95 \% \mathrm{CI}=1.18-2.39$, $P=0.004, P_{\text {heterogenity }}=0.73$ (Fig. 2). However, the sensitivity analyses in heterozygote comparison AG vs. GG and homozygote comparison AA vs. GG 
Table 3 Summary of the odds ratio (OR) for genetic contrasts in the polymorphism of IRS-1/IRS-2 gene and Polycystic ovary syndrome

\begin{tabular}{|c|c|c|c|c|c|c|c|c|c|}
\hline \multirow{2}{*}{$\begin{array}{c}\text { IRS } \\
\text { polymorphism }\end{array}$} & \multirow{2}{*}{$\begin{array}{l}\text { Genetic } \\
\text { contrast }\end{array}$} & \multirow{2}{*}{$\begin{array}{c}\text { Population } \\
\text { and subgroups } \\
\text { under analysis }\end{array}$} & \multirow{2}{*}{$\begin{array}{l}\text { Studies } \\
\text { (n) }\end{array}$} & \multicolumn{2}{|c|}{ OR $(95 \% \mathrm{CI})$} & \multirow{2}{*}{$\begin{array}{l}\mathrm{Q} \text { test }^{\mathrm{a}} \\
P \text {-value }\end{array}$} & \multirow{2}{*}{$\mathrm{I}^{2}(\%)$} & \multirow{2}{*}{$\begin{array}{l}\text { Begg's } \\
\text { test } \\
P \text {-value }\end{array}$} & \multirow{2}{*}{$\begin{array}{l}\text { Egger's } \\
\text { test } \\
P \text {-value }\end{array}$} \\
\hline & & & & Fixed-model & Random-model & & & & \\
\hline \multirow{8}{*}{$\begin{array}{l}\text { IRS-1 } \\
\text { (Gly972Arg) }\end{array}$} & \multirow[t]{2}{*}{$\mathrm{AA}+\mathrm{AG}$ vs. GG } & All & 15 & $2.14(1.66,2.75)$ & $2.17(1.47,3.19)$ & 0.02 & 50.0 & 0.584 & 0.918 \\
\hline & & All in HWE & 13 & $2.03(1.55,2.67)$ & $2.12(1.38,3.25)$ & 0.01 & 53.0 & 0.951 & 0.565 \\
\hline & \multirow[t]{2}{*}{ AG vs. GG } & All & 15 & $2.12(1.64,2.74)$ & $2.16(1.46,3.19)$ & 0.02 & 50.0 & 0.661 & 0.906 \\
\hline & & All in HWE & 13 & $2.03(1.54,2.67)$ & $2.11(1.37,3.25)$ & 0.01 & 52.0 & 0.951 & 0.547 \\
\hline & \multirow[t]{2}{*}{ AA vs. GG } & All & 15 & $2.62(0.86,8.02)$ & $2.62(0.86,7.98)$ & 0.95 & 0.00 & 0.296 & 0.311 \\
\hline & & All in HWE & 13 & $2.53(0.51,12.53)$ & $2.55(0.52,12.52)$ & 0.84 & 0.00 & 1.000 & ------'b \\
\hline & \multirow[t]{2}{*}{ A vs. G } & All & 15 & $2.02(1.59,2.57)$ & $1.97(1.45,2.67)$ & 0.14 & 30.0 & 0.324 & 0.475 \\
\hline & & All in HWE & 13 & $1.94(1.49,2.51)$ & $1.91(1.36,2.68)$ & 0.12 & 32.0 & 0.669 & 0.957 \\
\hline \multirow{10}{*}{$\begin{array}{l}\text { IRS-2 } \\
\text { (Gly1057Asp) }\end{array}$} & \multirow[t]{2}{*}{$\mathrm{AA}+\mathrm{AG}$ vs. $\mathrm{GG}$} & All & 5 & $1.06(0.81,1.39)$ & $1.09(0.66,1.80)$ & 0.01 & 70.0 & 0.806 & 0.464 \\
\hline & & All in HWE & 3 & $0.76(0.55,1.07)$ & $0.76(0.55,1.07)$ & 0.44 & 0.00 & 1.000 & 0.976 \\
\hline & \multirow[t]{2}{*}{ AG vs. GG } & All & 5 & $0.90(0.67,1.20)$ & $0.93(0.60,1.43)$ & 0.08 & 53.0 & 0.462 & 0.360 \\
\hline & & All in HWE & 3 & $0.69(0.48,0.98)$ & $0.69(0.48,0.98)$ & 0.46 & 0.00 & 1.000 & 0.916 \\
\hline & \multirow[t]{2}{*}{ AA vs. AG+GG } & All & 5 & $1.68(1.18,2.39)$ & $1.67(1.17,2.39)$ & 0.73 & 0.00 & 0.086 & 0.025 \\
\hline & & All in HWE & 3 & $1.32(0.80,2.39)$ & $1.32(0.79,2.20)$ & 0.87 & 0.00 & 1.000 & 0.812 \\
\hline & \multirow[t]{2}{*}{ AA vs.GG } & All & 5 & $1.70(1.13,2.54)$ & $1.63(1.00,2.68)$ & 0.24 & 28.0 & 0.086 & 0.024 \\
\hline & & All in HWE & 3 & $1.12(0.65,1.94)$ & $1.13(0.66,1.93)$ & 0.76 & 0.00 & 1.000 & 0.783 \\
\hline & \multirow[t]{2}{*}{ A vs. G } & All & 5 & $1.20(0.99,1.46)$ & $1.18(0.82,1.72)$ & 0.006 & 72.0 & 0.806 & 0.544 \\
\hline & & All in HWE & 3 & $0.92(0.72,1.18)$ & $0.92(0.72,1.18)$ & 0.47 & 0.00 & 1.000 & 0.917 \\
\hline
\end{tabular}

${ }^{\mathrm{a}}$ The significance level ( $P$-value) of heterogeneity test (Q-test). ${ }^{\mathrm{b}}$ the $P$-value of Egger's test in this model could not be calculated. HWE, Hardy-Weinberg equilibrium; All, including all the studies; All in HWE, having excluded studies explicit violating of HWE

revealed the opposite outcomes (in fixed effect model (FE) $\mathrm{OR}_{\mathrm{AGvSGG}}=0.69 \quad[95 \%$ CI $(0.48,0.98)] ; \mathrm{FE}$ $\mathrm{OR}_{\mathrm{AAvsGG}}=1.13[95 \% \mathrm{CI}(0.66,1.93)]$, respectively).

\section{Publication bias}

Begger's funnel plot and Egger's test were performed to assess publication bias of the literature. The results of the Begg's test and Egger's test on Gly972Arg polymorphism of the IRS-1 indicated no statistically significant evidence of publication bias. The Begg's tests and Egger's tests on Gly1057Asp polymorphism showed no obvious publication bias in dominant model, heterozygote comparison AG vs. GG, and allele A vs. G. However, the results of the Begg's test and Egger's test on homozygote comparison AA vs. GG in Gly1057Asp polymorphism were $P=0.0806 ; P=0.024$, respectively. Funnel plots were in agreement with the results of the Begg's test and Egger's test.

\section{Discussion}

PCOS have profound peripheral insulin resistance, and a sustantially increased risk for T2DM, indepen- dent of obesity, due to a postbinding defect in insulin signaling [7, 30-32]. Current evidence suggests that IRS-1/2-mediated activation of phosphatidylinositol 3-kinase (PI3-kinase) controls insulin-mediated glucose transport and carbohydrate metabolism [33-37]. Several studies have shown that allelic variants in the IRS genes IRS-1 Gly972Arg and IRS-2 Gly1057Asp may play a functional role on the insulin-resistance, cholesterol metabolism, and metabolic perturbations $[12,13]$. A recent genome-wide association (GWA) study of PCOS in Han Chinese failed to detect associations between the polymorphism of IRS gene and PCOS [38]. It maybe conjectured that the IRS-1/2 gene variant frequencies are infrequent, which suggests a possible role of ethnic differences in genetic backgrounds and the environment in which they live [39]. Overall, various studies did not confirm any association between polymorphisms in the above-mentioned genes and insulin-resistance of PCOS [11]. In order to resolve the conflict, we performed a meta-analysis from all eligible case-control studies to assess the purported associations. In IRS-1 Gly972Arg gene polymorphism, our results found that Arg972 allele might 


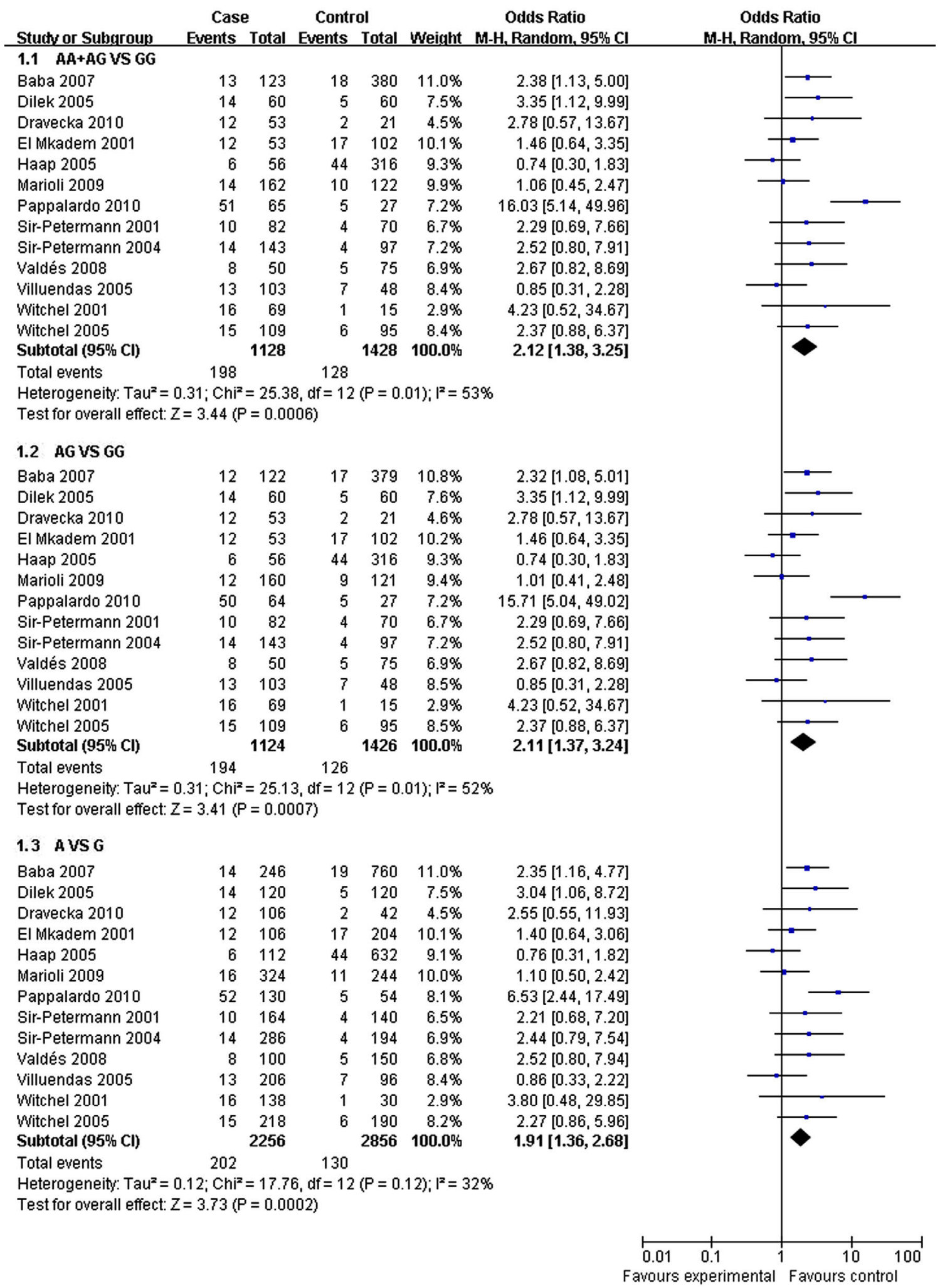

Fig. 1 Association between IRS-1 Gly972Arg gene polymorphism and susceptibility to PCOS. (1.1) Comparison of IRS-1 AA+AG genotypes with the GG genotype under the dominant model. (1.2) Heterozygote comparison of AG vs. GG model. (1.3) The allele contrast A vs. G of Gly972Arg polymorphism. The squares and horizontal lines correspond to the study-specific OR and $95 \%$ CI. The area of squares reflects the study specific weight (inverse of the variance). The diamond represents the summary OR and $95 \%$ CI. 


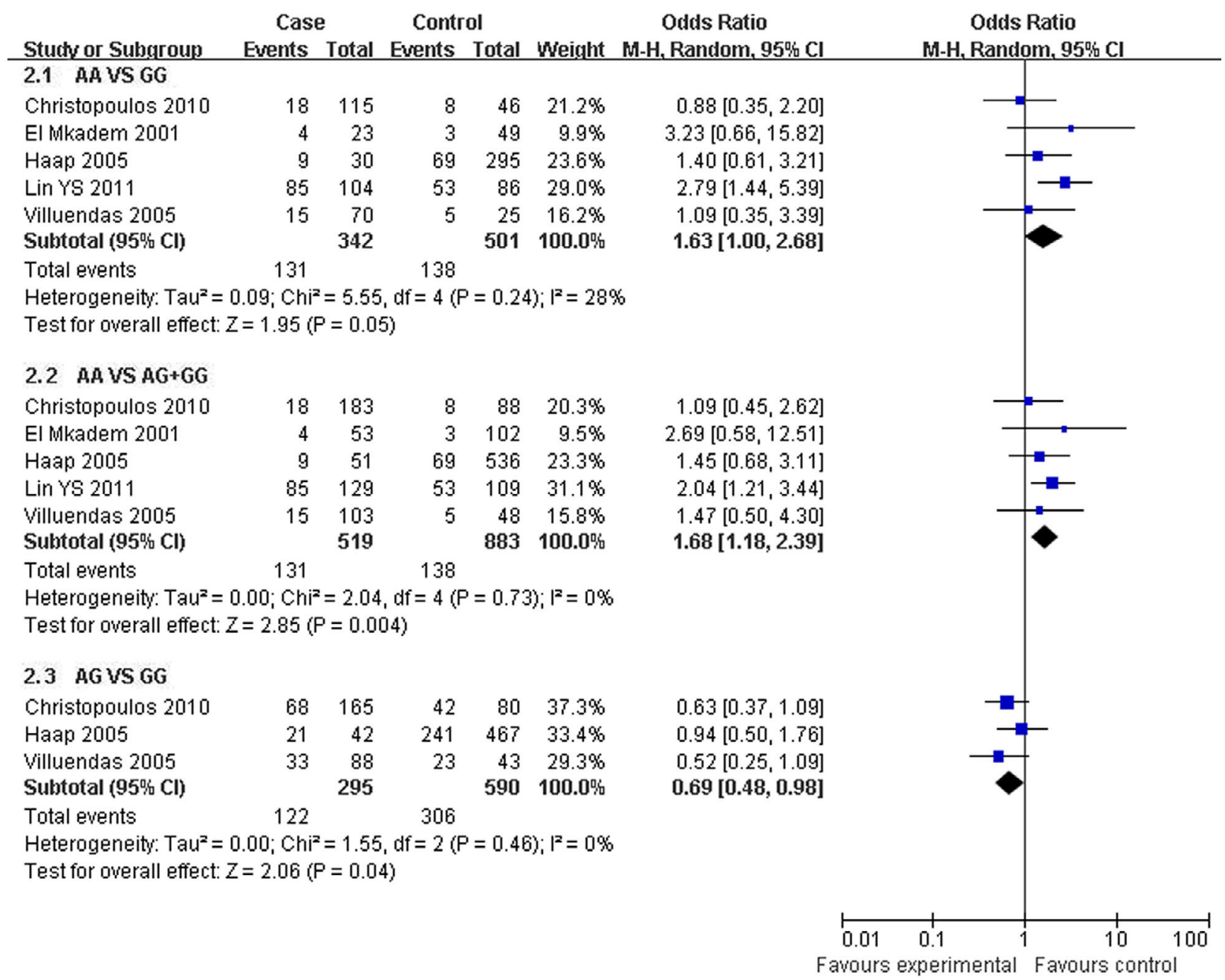

Fig. 2 Random effects OR estimates with the corresponding 95\%CI for IRS-2 Gly1057Asp polymorphism. (2.1) Overall analysis of co-dominant model comparison AA vs. GG. (2.2) Overall analysis of recessive model comparison AA vs. AG+GG. (2.3) The sensitivity analyses in heterozygote comparison AG vs. GG genetic model with excluded the studies of El Mkadem et al. and Lin YS et al.

be associated with the risk of PCOS. However, in IRS-2 Gly1057Asp gene polymorphism, our results failed to demonstrate an association between them.

\section{Gly972Arg polymorphism}

Sir-Petermann et al. have first reported a significant association between the IRS-1 Arg972 allele and PCOS in the Chilean population [29]. Ioannidis et al. published a meta-analysis on IRS-1 Gly972Arg polymorphism, and got conclusions that the Arg972 allele was associated with an increased risk for developing PCOS [16]. But recent four researches in the association between IRS-1 Gly972Arg polymorphism and PCOS still had different conclusions [19-22]. We excluded the studies done by Lin TC et al. and Christopoulos et al. due to explicit violation of Hardy-Weinberg equilibrium, so in our sensitivity-analysis study we may conclude that Gly972Arg polymorphism is associated with PCOS, and Arg972 allele might be considered a significant risk for PCOS. Since in lots of studies the gene frequency of AA genotype in PCOS was 0, the homozygote comparison AA vs. GG revealed the negtive outcomes.

\section{Gly1057Asp polymorphism}

El Mkadem et al., Villuendas et al., Christopoulos et al. and Haap $\mathrm{M}$ et al. did not find any association of the distribution of IRS-2 Gly1057Asp alleles with patients 
of PCOS, these study demonstrated that increased glucose levels or glucose homeostasis was observed in Asp allele PCOS carriers [11, 13, 21]. However, Lin YS et al. reported the homozygous IRS-2 Asp1057 allele was the common genotype and its frequency was higher in PCOS patients in the Taiwanese population, but this study was excluded in sensitivity analysis. The overall meta-analysis for homozygote comparison AA vs. GG revealed AA genotype might be a risk for PCOS. While removing Lin YS et al. study, our sensitivity analysis revealed the negative outcomes. The sensitivity analysis of AG vs. GG genotype revealed positive outcome. This result might be explained the homozygous genotype of Asp1057 allele is very rare in Caucasian [13, 19], but very common in Taiwanese [18].

Like all meta-analysis, some limitations of this metaanalysis should be monitored. First, all the eligible studies were limited to English papers. It is likely that some relevant published reports in other languages that might meet the inclusion criteria were missed. Second, individual data in our studies were not adjusted by those covariates including race, region, age, sex, body mass index, and other biochemical indicator, so a more precise analysis should be conducted if we increase samples and estimate them based on adjusted analysis. Third, we should also admit the possibility of publication bias. Some studies may not have been indexed online or may be unpublished so far. Publication bias would tend to result in the disappearance of small studies with negative results. Fourth, as studies of the two polymorphisms in Asia population were limited, subgroup analyses were not considered in our research. Fifth, the studies included in each comparison of our research were limited, the conclusion was not that reliable, which needs to be further confirmed by further studies.

In summary, our meta-analysis confirmed a significant association between the IRS-1 Gly972Arg polymorphism and PCOS, and this variation might be considered as a risk factor for PCOS. However, no significant association was detected between IRS-2 Gly1057Asp polymorphism and PCOS. Considering that the conclusion was based on limited studies with relatively small samples, larger well-designed studies involving IRS-2 Gly1057Asp polymorphisms subjects in different ethnic populations are required. Moreover, further investigation of protein levels may help to clarify the influence of genetic variation in the pathogenesis and gene-gene and gene-environment interactions should also be considered in future.

\section{Acknowledgment}

This research project was supported by grants from The Natural Science Foundation of Jiangsu Province, China (BK2010121).

\section{Conflict of Interest Statement}

The authors declare that they have no conflict of interest.

\section{References}

1. Ehrmann DA (2005) Polycystic ovary syndrome. $N$ Engl J Med 352: 1223-1236.

2. Norman RJ, Dewailly D, Legro RS, Hickey TE (2007) Polycystic ovary syndrome. Lancet 370: 685-697.

3. Legro RS (2003) Polycystic ovary syndrome and cardiovascular disease: a premature association? Endocrinol Rev 24: 302-312.

4. Legro RS, Strauss JF (2002) Molecular progress in infertility: polycystic ovary syndrome. Fertil Steril 78: 569-576.

5. Legro RS, Gnatuk CL, Kunselman AR, Dunaif A (2005) Changes in glucose tolerance over time in women with polycystic ovary syndrome: a controlled study. J Clin Endocrinol Metab 90: 3236-3242.

6. Maitra A, Pingle RR, Menon PS, Naik V, Gokral JS, et al. (2001) Dyslipidemia with particular regard to apolipoprotein profile in association with polycystic ovary syndrome: A study among Indian women. Int J Fertil Womens Med 46: 271-277.

7. Dunaif $\mathrm{A}, \mathrm{Wu} \mathrm{X}$, Lee $\mathrm{A}$, Diamanti-Kandarakis $\mathrm{E}$ (2001) Defects in insulin receptor Signaling in vivo in the polycystic ovary syndrome (PCOS). Am J Physiol Endocrinol Metab 281: E392-E399.

8. Legro RS, (1998) Insulin resistance in polycystic ovary syndrome:treating a phenotype without a genotype. Mol Cell Endocrinol 145: 103-110.

9. Escobar-Morreale HF, Luque-Ramírez M, San Millán JL (2005) The molecular-genetic basis of functional hyperandrogenismand the polycystic ovary syndrome. Endocr Rev 26: 251-282.

10. Simoni M, Tempfer CB, Destenaves B, Fauser BC (2008) Functional genetic polymorphisms and female reproductive disorders: Part I: Polycystic ovary syndrome and ovarian response. Hum Reprod Update 14: 
459-484.

11. Ehrmann DA, Tang X, Yoshiuchi I, Cox NJ, Bell GI (2002) Relationship of insulin receptor substrate-1 and -2 genotypes to phenotypic features of polycystic ovary syndrome. J Clin Endocrinol Metab 87: 4297-4300.

12. El Mkadem SA, Lautier C, Macari F, Molinari N, Lefebvre P, et al. (2001) Role of allelic variants Gly972Arg of IRS-1 and Gly1057Asp of IRS-2 in moderate-to-severe insulin resistance of women with polycystic ovary syndrome. Diabetes 50: 2164-2168.

13. Villuendas G, Botella-Carretero JI, Roldan B, Sancho J, Escobar-Morreale HF, et al. (2005) Polymorphisms in the insulin receptor substrate-1 (IRS-1) gene and the insulin receptor substrate-2 (IRS-2) gene influence glucose homeostasis and body mass index in women with polycystic ovary syndrome and non-hyperandrogenic controls. Hum Reprod 20: 3184-3191.

14. Dilek S, Ertunc D, Tok EC, Erdal EM, Aktas A (2005) Association of Gly972Arg variant of insulin receptor substrate-1 with metabolic features in women with polycystic ovary syndrome. Fertil Steril 84: 407-412.

15. Lin TC, Yen JM, Gong KB, Kuo TC, Ku DC, et al. (2006) Abnormal glucose tolerance and insulin resistance in polycystic ovary syndrome amongst the Taiwanese population not correlated with insulin receptor substrate-1 Gly972Arg/Ala513Pro polymorphism. BMC Med Genet 7: 36.

16. Ioannidis A, Ikonomi E, Niki L, Dimou, Douma L, et al. (2010) Polymorphisms of the insulin receptor and the insulin receptor substrates genes in polycystic ovary syndrome: A Mendelian randomization meta-analysis. Mol Genet Metab 99: 174-183.

17. Lau J, Ioannidis JP, Schmid CH (1997) Quantitative synthesis in systematic reviews. Ann Intern Med 127: 820-826.

18. Lin YS, Tsai SJ, Lin MW, Yang CT, Huang MF, et al. (2011) Interleukin-6 as an Early Chronic Inflammatory Marker in Polycystic Ovary Syndrome with Insulin Receptor Substrate-2 Polymorphism. Am J Reprod Immunol 66: 527-533.

19. Christopoulos P, Mastorakos G, Gazouli M, Deligeoroglou E, Katsikis I, et al. (2010) Study of association of IRS-1 and IRS-2 genes polymorphisms with clinical and metabolic features in women with polycystic ovary syndrome. Is there an impact? Gynecol Endocrinol 26: 698-703.

20. Pappalardo MA, Russo GT, Pedone A, Pizzo A, Borrielli I, et al. (2010) Very high frequency of the polymorphism for the insulin receptor substrate 1 (IRS-1) at codon 972(glycine972arginine) in Southern Italian women with polycystic ovary syndrome. Horm Metab Res 42: 575-584.

21. Dravecká I, Lazúrová I, Habalová V (2010) The prevalence of Gly972Arg and C825T polymorphisms in Slovak women with polycystic ovary syndrome and their relation to the metabolic syndrome. Gynecol Endocrinol 26: 356-360.

22. Marioli DJ, Koika V, Adonakis GL, Saltamavros AD, Karela A, et al. (2010) No association of the G972S polymorphism of the insulin receptor substrate-1 gene with polycystic ovary syndrome in lean PCOS women with biochemical hyperandrogenemia. Arch Gynecol Obstet 281: 1045-1049.

23. Haap M, Machicao F, Stefan N, Thamer C, Tschritter O, et al. (2005) Genetic determinants of insulin action in polycystic ovary syndrome. Exp Clin Endocrinol Diabetes 113: 275-281.

24. Valdés P, Cerda A, Barrenechea C, Kehr M, Soto C, et al. (2008) No association between common Gly972Arg variant of the insulin receptor substrate- 1 and polycystic ovary syndrome in Southern Chilean women. Clin Chim Acta 390: 63-66.

25. Baba T, Endo T, Sata F, Honnma H, Kitajima Y, et al. (2007) Polycystic ovary syndrome is associated with genetic polymorphism in the insulin signaling gene IRS-1 but not ENPP1 in a Japanese population. Life Sci 81: 850-854.

26. Witchel SF, Kahsar-Miller M, Aston CE, White C, Azziz R (2005) Prevalence of CYP21 mutations and IRS1 variant among women with polycystic ovary syndrome and adrenal androgen excess. Fertil Steril 83: 371-375.

27. Sir-Petermann T, Angel B, Maliqueo M, Santos JL, Riesco MV, et al. (2004) Insulin Secretion in Women Who Have Polycystic Ovary Syndrome and Carry the Gly972Arg Variant of Insulin Receptor Substrate-1 in Response to a High-Glycemic or Low-Glycemic Carbohydrate Load. Nutrition 20: 905-910.

28. Witchel SF, Smith R, Tomboc M, Aston CE (2001) Candidate gene analysis in premature pubarche and adolescent hyperandrogenism. Fertil Steril 75: 724730 .

29. Sir-Petermann T, Pérez-Bravo F, Angel B, Maliqueo M, Calvillan M, et al. (2001) G972R polymorphism of IRS-1 in women with polycystic ovary syndrome. Diabetologia 44: 1200-1201.

30. Ciaraldi TP, el-Roeiy A, Madar Z, Reichart D, Olefsky JM, et al. (1992) Cellular mechanisms of insulin resistance in polycystic ovarian syn-drome. J Clin Endocrinol Metab 75: 577-583.

31. Dunaif A, Segal KR, Shelley DR, Green G, Dobrjansky A, et al. (1992) Evidence for distinctive and intrinsic defects in insulin action in polycystic ovary syndrome. Diabetes 41: 1257-1266.

32. White MF (1998) The IRS-signaling system: a network of docking proteins that mediate insulin and cytokine action. Recent Prog Horm Res 53: 119-138.

33. Kanai F, Ito K, Todaka M (1993) Insulin-stimulated GLUT4 translocation is relevant to the phosphorylation of IRS-1 and the activity of PI3-kinase. Biochem Biophys Res Commun 195: 762-768. 
34. Okada T, Kawano Y, Sakakibara T, Osamu H, Ui M (1994) Essential role of phosphatidylinositol 3-kinase in insulin-induced glucose transport and antilipoysis in rat adipocytes. J Biol Chem 269: 3568-3573.

35. Cheatham B, Vlahos CJ, Cheatham L, Wang L, Blenis J, et al. (1994) Phosphatidylinositol 3-kinase activation is required for insulin stimulation of pp70 S6 kinase, DNA synthesis, and glucose transporter translocation. Mol Cell Biol 14: 4902-4911.

36. Marchand-Brustel Y, Gautier N, Cormont M, Van Obberghen E (1995) Wortmannin inhibits the action of insulin but not that of okadaic acid in skeletal muscle.
Comparison with fat cells. Endocrinology 136: 35643570 .

37. Lawrence JC, Roach PJ (1997) New insights into the role and mechanism of glycogen synthase activation by insulin. Diabetes 46: 541-547.

38. Chen ZJ, Zhao H, He L, Shi Y, Qin Y, et al. (2011) Genome-wide association study identifies susceptibility loci for polycystic ovary syndrome on chromosome 2p16.3, 2p21 and 9q33.3. Nat Genet 43: 55-59.

39. Hirschhorn JN, Lohmueller K, Byrne E, Hirschhorn K (2002) A comprehensive review of genetic association studies. Genet Med 4: 45-61. 